\title{
Model Predictive Control of Hybrid Transformer with Matrix Converter
}

\section{Pawel Szcześniak, Grzegorz Tadra, Zbigniew Fedyczak}

Institute of Electrical Engineering, University of Zielona Góra

ul. prof. Z. Szafrana 2, 65-516 Zielona Góra, Poland

P.Szczesniak@iee.uz.zgora.pl,g.tadra@uesa.pl,Z.Fedyczak@iee.uz.zgora.pl

\begin{abstract}
This paper proposes a model predictive control for a hybrid transformer (HT) with matrix converter $(M C)$. The proposed HT system is composed of a power transformer connected to a power electronic converter which controls the output voltage on the secondary side. The proposed solution of $H T$ is used to resolve power quality issues and power flow control in the electrical power distribution system. The advantages of predictive control are its very simple realization and the possibility to optimize various predefined criteria. Presented in the paperr is a discussion of the conception of a model predictive control strategy to compensate for voltage sags, swells and harmonics on the grid side by providing continuous AC voltage regulation of the HT. Also, presented are the preliminary simulation results, which verify the high performance of the proposed predictive control.
\end{abstract}

Keywords: Model Predictive Control; Power Transformer; Matrix Converter; Voltage Compensator

\section{Introduction}

Grid voltage sags and swells that propagate in the distribution grid may have a great impact on electric devices, and may consequently reduce their life cycles and generate additional economic costs [1], [2]. Modern systems of industrial plants are being established with high-tech equipment for increased productivity that requires a higher demand for quality power. Reducing the impact of supply voltage changes on the operation of electrical devices requires the use of various improvements throughout the power energy system. Two main compensation methods of voltage-disturbance in power systems occur: parallel - "current" (SVC - static VAR compensator and STATCOM - static synchronous compensator,) and series - "voltage" (DVR - Dynamic Voltage Restorer). In addition, conventional transformer with a tap changer are used to compensate seasonal voltage changes or low incidence occurances. 
One of the solutions for power quality problems is the use of power electronic systems that enable various ways to compensate for existing disturbances [3]-[5]. The group of compensators which are based on power electric devices (STATCOM, SVC, and DVR) guarantees good dynamic properties of the compensation process. Depending on voltage compensators position in the electrical system we can distinguish: (i) separate compensator - local, (ii) group compensator and (iii) central compensator. The above methods of compensators arrangements are presented in Fig. 1. Separated compensation - applies to direct cooperation between compensator and load. The group and central compensation - allow the use compensators for a selected industrial plants, buildings or parts of the power network.

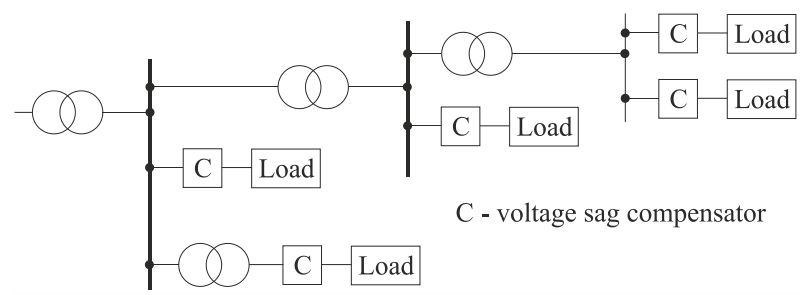

(a)

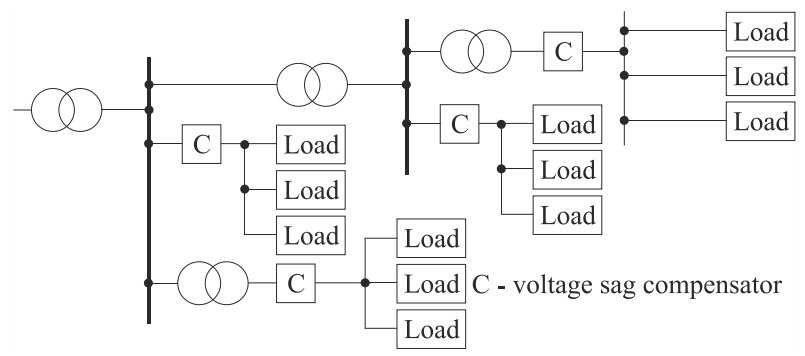

(b)

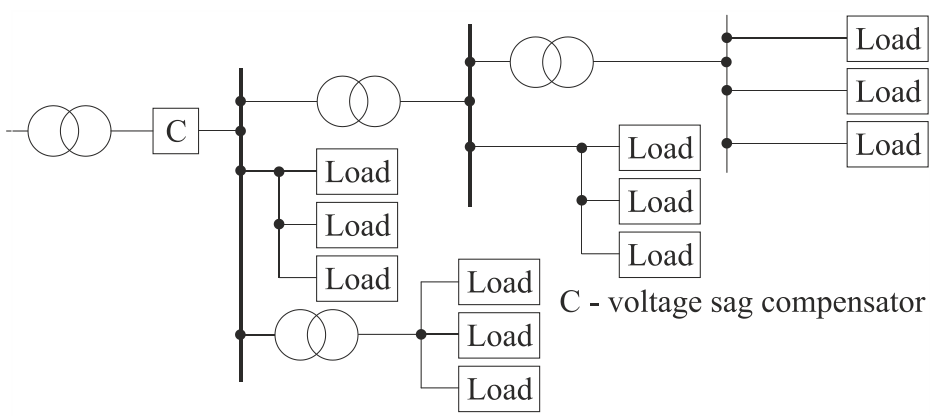

(c)

Figure 1

Methods of location of voltage compensators: local (a), group (b), central (c) 
In addition, the concept of various hybrid transformers has been proposed as a compensator in AC voltage amplitude changes [6]-[10]. HT is devices where a conventional electromagnetic transformer cooperates with a pulse-width modulation (PWM) AC/AC converter. In the literature, one can find many different solutions of hybrid compensators [10]-[12]. In this publication, HT with a matrix converter will be considered [10].

Proposed in publication [10] is the concept of a HT with a MC, but without indication of any automatic regulation algorithm in a closed feedback loop. In this article, static parameters such as the voltage regulation range and its phase shift angle for Space Vector Modulation [13] control have been determined and the basic control characteristics have been shown. In addition, examples of compensation for symmetrical and asymmetrical AC voltage changes have been presented. For symmetrical voltage variations in each of the supply lines, good compensating properties were obtained. However, for compensating unbalanced voltage distortions, the obtained results were not satisfactory. In the output voltages after compensation there were additional low orders harmonics. The closed loop control strategy with PI regulators has been proposed in the reference [11] and [12]. In presented algorithm the detection of both input and output voltages and the determination of compensating signals is requires. The proposed control was quite complex, and it requires optimization of PI regulator settings, which also depended on the parameters of the transformer used. Additionally, in order to precisely shape compensating signals with unsymmetrical strained supply voltage, complex algorithms of PLL synchronization loops should be used [14, 15].The obtained results presented in [11] and [12] for the compensation of asymmetric voltage sag indicates a lack of full compensation. Similar as in [10] the lower orders of voltage harmonics occur in the output voltages.

In the scientific literature many methods have been proposed for controlling power converters. Among them, one can distinguish: hysteresis control, linear, sliding, predictive, non-linear and using artificial intelligence. The indicated methods are characterized by different complexity and properties. More complex methods require significantly higher computational power of dedicated control platforms (DSP, FPGA), but they significantly improve the properties of controlled systems. In recent years, a lot of work has been devoted to the development of non-linear methods and with the use of artificial intelligence in various fields of technology such as automation, process control, telecommunications, logistics, transport and optimization of networks and processes [16]-[24].

With the control methods developed in recent times, predictive control has gained a lot of interest especially in the applications of power electronic converters and electric drives [25]. Predictive control includes a very wide group of controllers with very different approaches to operation. However, a common approach for all types of predictive control is modeling of the controlled system and determining the future state of the system, including the optimization of control criteria [25]. 
In this paper the model predictive control of a hybrid transformer with matrix converter is proposed. Model-based predictive control has been commonly used as a method to control load current, motor speed and torque control by different types of power electronic converter [25]. Furthermore, using the MPC in converters control allows control of different converter parameters such as: the switching frequency, input power factor $(\mathrm{PF})$ and common mode voltage. Those parameters are control depending on the assumed cost function. Additionally, the MPC is usually employed in parallel compensators working as STATCOM to shape the compensator currents [26]. The novelty of this paper is the use of MPC in a series voltage compensator to shape the compensator voltages. The working principle of the MPC in the proposed AC voltage conditioner is to generation of the compensation voltage signals at different voltage distortion conditions. In addition to the generation of compensation voltages, an additional objective function has been introduced related to the adjustment of the input power factor. The proposed methods for controlling the series AC voltage compensator have advantages to classical control methods. A significant advantage is the compensation of both changes in voltage amplitude as well as asymmetrical and harmonic distortions. In addition, better dynamic properties are achieved.

Because the transformer has unity voltage ratio and the grid voltages are measured on the transformer secondary side, only the matrix converter with input and output filters models are included in the proposed control algorithm. In the presented preliminary stage of research, the parameters of the electromagnetic transformer were not taken into account. The influence of transformer parameters on the prediction of grid currents must be analyzed in the future in more detailed studies. At the current stage of research, tests of the proposed prediction algorithm with symmetrical and unsymmetrical voltage distortions will be carried out.

The structure of the paper is organized as follows. Sections 2 introduce hybrid transformer witch matrix converter topology. The main idea of the proposed control technique based on Model Predictive Control is shown in Section 3. In this chapter, the input and output filter models were determined and the prediction algorithm based on the allowed combinations of matrix converter switch states was defined. In addition, the method of determining compensation voltages and minimizing the set target functions has been defined. The results of simulation verification of the system are presented in Section 4. Finally, Section 5 concludes the paper and shows possible directions for future research.

\section{Proposed HT with MC}

The main HT system with MC proposed in accordance with [10] is shown in Fig. 2. A fundamental component in the provision of reliable electricity to the enduser is the distribution transformer with two secondary windings. The output 
voltage of the whole $\mathrm{HT}$ is the sum of the MC output voltage and the second secondary winding voltage of the transformer. The transformer voltage ratios between primary and each secondary winding of the transformer are 1:1. Such voltage ratios allow the MC to be switched-off via bypass switches, while working with nominal amplitude value of the grid voltage. The MC can adjust the amplitude of the output voltage in the range from 0 to 0.866 times the supply voltage and adjust the phase of the output voltage within the whole range of its voltage change [13].

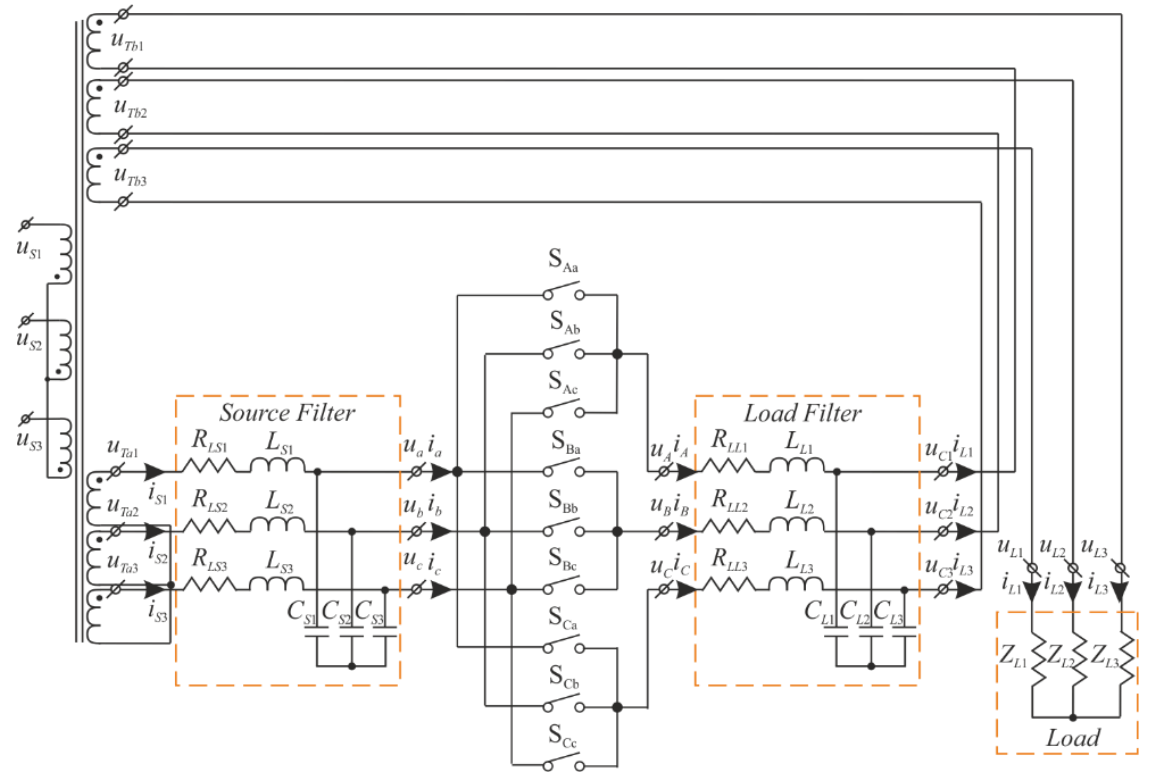

Figure 2

Proposed Hybrid Transformer (HT) with Matrix Converter (MC)

\section{Model Predictive Control}

The main characteristic of predictive control is the use of a model of the system for predicting the future behavior of controlled variables [25]. Obtained information is used by the control unit to obtain the optimal switch configuration, according to a predefined optimization criterion. Therefore, in the MPC, the controller model consists of: 1) a discrete input filter model; 2) the model of the converter determining the relations between the input and output terminals, 3) the discrete output filter model; 4) optimization criteria. On the basis of the mathematical model of the system, one state is determined for all allowed combinations of connectors, for which the optimization criterion has a minimum 
value. The mathematical model of individual components and optimization criteria are described in this chapter.

We assume in this paper an idealized transformer with two taps both with a voltage ratio of 1:1. All three-phase currents and voltages are written in a complex form using Clark transformation:

$\underline{x}=x_{\alpha}+j x_{\beta} \Leftrightarrow\left[\begin{array}{l}x_{\alpha} \\ x_{\beta}\end{array}\right]=\frac{2}{3}\left[\begin{array}{ccc}1 & -\frac{1}{2} & -\frac{1}{2} \\ 0 & \frac{\sqrt{3}}{2} & -\frac{\sqrt{3}}{2}\end{array}\right]\left[\begin{array}{l}x_{1} \\ x_{2} \\ x_{3}\end{array}\right]$

The continuous time system of source and load filter can be rewritten as follows:

$\frac{d}{d t} \mathbf{x}(t)=\mathbf{A} \mathbf{x}(t)+\mathbf{B u}(t) \Leftrightarrow s \mathbf{x}(s)=\mathbf{A} \mathbf{x}(s)+\mathbf{B u}(s)$

The input filter is described by the following equation:

$\left[\begin{array}{c}\frac{d \underline{u}_{a b c}}{d t} \\ \frac{d \underline{i}_{S}}{d t}\end{array}\right]=\left[\begin{array}{cc}0 & \frac{1}{C_{S}} \\ -\frac{1}{L_{S}} & -\frac{R_{L S}}{L_{S}}\end{array}\right]\left[\begin{array}{c}\underline{u}_{a b c} \\ \underline{i}_{S}\end{array}\right]+\left[\begin{array}{cc}0 & -\frac{1}{C_{S}} \\ \frac{1}{L_{S}} & 0\end{array}\right]\left[\begin{array}{c}\underline{u}_{S} \\ \underline{i}_{a b c}\end{array}\right]$

where: $\underline{u}_{a b c}-$ the voltage at the source filter capacitors (MC input voltage), $\underline{i}_{S}-$ the source current, $\underline{u}_{S}$ - the source voltage $\left(\underline{u}_{S}=\underline{v}_{T a}\right), \underline{i}_{a b c}-$ the MC input current. All variables are described in complex form $x_{\alpha}+j x_{\beta}$. Similar, the output filter model has the following form:

$\left[\begin{array}{c}\frac{d \underline{u}_{C}}{d t} \\ \frac{d \underline{i}_{A B C}}{d t}\end{array}\right]=\left[\begin{array}{cc}0 & \frac{1}{C_{L}} \\ -\frac{1}{L_{L}} & -\frac{R_{L L}}{L_{L}}\end{array}\right]\left[\begin{array}{c}\underline{u}_{C} \\ \underline{i}_{A B C}\end{array}\right]+\left[\begin{array}{cc}0 & -\frac{1}{C_{L}} \\ \frac{1}{L_{L}} & 0\end{array}\right]\left[\begin{array}{c}\underline{u}_{A B C} \\ \underline{i}_{L}\end{array}\right]$

where: $\underline{u}_{A B C}-$ the MC output voltage, $\underline{i}_{L}-$ the load current, $\underline{u}_{C}$ - the compensation voltage, $\underline{i}_{A B C}$ - the MC output current.

Using a bilinear transformation, we replace " $s$ " with the following relationship:

$s=\frac{2}{T_{D}} \frac{(z-1)}{(z+1)}$

where $T_{D}$ is the discretization time, we obtained digital space equations:

$z x(z)=\mathbf{A}_{\mathrm{d}} x(z)+\mathbf{B}_{\mathrm{d}} u(z)$

Individual matrices after digitization have the following form:

$$
\begin{aligned}
& \mathbf{A}_{\mathrm{d}}=\left(\frac{2}{T_{D}} \mathbf{I}-\mathrm{A}\right)^{-1}\left(\frac{2}{T_{D}} \mathbf{I}+\mathbf{A}\right) \\
& \mathbf{B}_{\mathrm{d}}=\left(\frac{2}{T_{D}} \mathbf{I}-\mathbf{A}\right)^{-1} \mathbf{B}
\end{aligned}
$$

where I - unit matrix. Based on equation (6) we get the difference equations:

$$
\left[\begin{array}{c}
\underline{u}_{a b c}(k+1) \\
\underline{i}_{S}(k+1)
\end{array}\right]=\mathbf{A}_{S d}\left[\begin{array}{c}
\underline{u}_{a b c}(k) \\
\underline{i}_{S}(k)
\end{array}\right]+\mathbf{B}_{S d}\left[\begin{array}{c}
\underline{u}_{S}(k) \\
\underline{i}_{a b c}(k)
\end{array}\right]
$$




$$
\left[\begin{array}{c}
\underline{u}_{C}(k+1) \\
\underline{i}_{A B C}(k+1)
\end{array}\right]=\mathbf{A}_{L d}\left[\begin{array}{c}
\underline{u}_{C}(k) \\
\underline{i}_{A B C}(k)
\end{array}\right]+\mathbf{B}_{L d}\left[\begin{array}{c}
\underline{u}_{A B C}(k) \\
\underline{i}_{L}(k)
\end{array}\right]
$$

where $\mathbf{A}_{S d}, \mathbf{B}_{S d}, \mathbf{A}_{L d}, \mathbf{B}_{L d}$ - matrices of input and output filter space model after the digitization, respectively. Based on the models described in the recursive formulas (9) and (10), the values of the predictive source current $\underline{i}_{S}$ and the compensator output voltage $\underline{u}_{C}$ are determined as follows:

$$
\begin{array}{r}
\underline{i}_{S}(k+1)=a_{S 21} \underline{u}_{a b c}(k)+a_{S 22} \underline{i}_{S}(k)+b_{S 21} \underline{u}_{S}(k)+b_{S 22} \underline{i}_{a b c}(k) \\
\underline{u}_{C}(k+1)=a_{L 11} \underline{u}_{C}(k)+a_{L 12} \underline{i}_{A B C}(k)+b_{L 11} \underline{u}_{A B C}(k)+b_{S 12} \underline{i}_{L}(k)
\end{array}
$$

where: $a_{S 21}, a_{S 22}, b_{S 21}, b_{S 22}$ are the appropriate elements of the matrix $\mathbf{A}_{S}$ and $\mathbf{B}_{S}$; $a_{L 21}, a_{L 22}, b_{L 21}, b_{L 22}$ are the appropriate elements of the matrix $\mathbf{A}_{L}$ and $\mathbf{B}_{L}$.

Other values in the model are measured directly in the system or calculated based on the following relationships:

$$
\begin{aligned}
& i_{a b c}=\mathbf{D}^{\mathrm{T}} i_{A B C} \\
& u_{A B C}=\mathbf{D} u_{a b c} \\
& \mathbf{D}=\left[\begin{array}{lll}
s_{a A} & s_{b A} & s_{c A} \\
s_{a B} & s_{b B} & s_{c B} \\
s_{a C} & s_{b C} & s_{c C}
\end{array}\right]
\end{aligned}
$$

In order to compensate for variations in the source voltages (voltage sag/swell, variations, harmonic distortion), the reference compensating voltage signals should be generated at the output of the MC $\left(u_{\text {Cref }}\right)$, which signals are the differences between the expected value at the HT output $\left(u_{\text {Lref }}\right)$ and the measured value of the supply network $\left(u_{S}\right)$.

$u_{\text {Cref }}=u_{\text {Lref }}-u_{S}$

Hence, determining the compensation signal is relatively simple and results from the natural difference of the expected and measured signal. The HT output voltage is the sum of compensator and source voltages:

$\underline{u}_{L}=\underline{u}_{C}+\underline{u}_{S}$

In the prediction algorithm, in the next iteration step, 27 different solutions for 27 allowed switching combinations of MC switches are checked (Table 1).

Then, based on the obtained results, the cost function $g$ is minimized [25], [27]. It is possible to minimize many functions of costs. In the presented preliminary research approach, the cost function regarding the accuracy of shaping the output voltage " $g_{1}$ " and the shaping of the input power factor " $g_{2}$ " are minimized. Most applications request a unity input power factor, therefore, the input reactive power $Q_{S}$ value is minimized. The final cost function " $g$ " is the sum of the individual cost functions with the selected weighting factors $K_{1}, K_{2}$. 
Table 1

Switch configuration in the and corresponding output voltage and source current

\begin{tabular}{|c|c|c|c|c|c|c|c|c|c|c|c|c|c|c|}
\hline No & $\mathrm{a}$ & $\mathrm{b}$ & c & & $\begin{array}{l}a, S_{A} \\
S_{A c}\end{array}$ & & & $S_{B c}$ & & & $\begin{array}{l}a, S_{C} \\
S_{C c}\end{array}$ & & $u_{a b}, u_{b c}, u_{c a}$ & $i_{A}, \quad i_{B}, \quad i_{C}$ \\
\hline 1 & A & $\mathrm{A}$ & A & 1 & 0 & 0 & 1 & 0 & 0 & 1 & 0 & 0 & 0 & 0 \\
\hline 2 & B & B & B & 0 & 1 & 0 & 0 & 1 & 0 & 0 & 1 & 0 & $\begin{array}{ll}0 & 0\end{array}$ & 0 \\
\hline 3 & $\mathrm{C}$ & $\mathrm{C}$ & $\mathrm{C}$ & 1 & 0 & 0 & 1 & 0 & 0 & 1 & 0 & 0 & 0 & 0 \\
\hline 4 & A & $\mathrm{C}$ & $\mathrm{C}$ & 1 & 0 & 0 & 0 & 0 & 1 & 0 & 0 & 1 & $\begin{array}{lll}-u_{C A} & 0 & u_{C A} \\
\end{array}$ & $0 \quad-i_{a}$ \\
\hline 5 & B & $\mathrm{C}$ & $\mathrm{C}$ & 0 & 1 & 0 & 0 & 0 & 1 & 0 & 0 & 1 & $u_{B C} \quad 0 \quad-u_{B C}$ & $i_{a}-i_{a}$ \\
\hline 6 & B & $\mathrm{A}$ & $\mathrm{A}$ & 0 & 1 & 0 & 1 & 0 & 0 & 1 & 0 & 0 & $-u_{A B} 0 \quad u_{A B}$ & $-i_{a} i_{a} \quad 0$ \\
\hline 7 & $\mathrm{C}$ & A & A & 0 & 0 & 1 & 1 & 0 & 0 & 1 & 0 & 0 & $\begin{array}{lll}u_{C A} & 0 & -u_{C A} \\
\end{array}$ & $\begin{array}{lll}-i_{a} & 0 & i_{a} \\
\end{array}$ \\
\hline 8 & $\mathrm{C}$ & $\mathrm{B}$ & B & 0 & 0 & 1 & 0 & 1 & 0 & 0 & 1 & 0 & $-u_{B C} \quad 0 \quad u_{B C}$ & $0 \quad-i_{a} i_{a}$ \\
\hline 9 & A & $\mathrm{B}$ & $\mathrm{B}$ & 1 & 0 & 0 & 0 & 1 & 0 & 0 & 1 & 0 & $u_{A B} \quad 0 \quad-u_{A B}$ & $\begin{array}{lll}i_{a} & -i_{a} & 0\end{array}$ \\
\hline 10 & $\mathrm{C}$ & $\mathrm{A}$ & $\mathrm{C}$ & 0 & 0 & 1 & 1 & 0 & 0 & 0 & 0 & 1 & $\begin{array}{lll}u_{C A} & -u_{C A} & 0\end{array}$ & $\begin{array}{lll}i_{b} & 0 & -i_{b} \\
\end{array}$ \\
\hline 11 & $\mathrm{C}$ & $\mathrm{B}$ & $\mathrm{C}$ & 0 & 0 & 1 & 0 & 1 & 0 & 0 & 0 & 1 & $-u_{B C} u_{B C} \quad 0$ & $\begin{array}{lll}0 & i_{b} & -i_{b}\end{array}$ \\
\hline 12 & A & $\mathrm{B}$ & $\mathrm{A}$ & 1 & 0 & 0 & 0 & 1 & 0 & 1 & 0 & 0 & $u_{A B}-u_{A B} \quad 0$ & $-i_{b} i_{b} \quad 0$ \\
\hline 13 & A & $\mathrm{C}$ & A & 1 & 0 & 0 & 0 & 0 & 1 & 1 & 0 & 0 & $-u_{C A} u_{C A} \quad 0$ & $\begin{array}{lll}-i_{b} & 0 & i_{b} \\
\end{array}$ \\
\hline 14 & B & $\mathrm{C}$ & B & 0 & 1 & 0 & 0 & 0 & 1 & 0 & 1 & 0 & $u_{B C}-u_{B C} \quad 0$ & $0-i_{b} i_{b}$ \\
\hline 15 & $\mathrm{~B}$ & $\mathrm{~A}$ & $\mathrm{~B}$ & 0 & 1 & 0 & 1 & 0 & 0 & 0 & 1 & 0 & $-u_{A B} u_{A B} \quad 0$ & $\begin{array}{lll}i_{b} & -i_{b} & 0\end{array}$ \\
\hline 16 & $\mathrm{C}$ & $\mathrm{C}$ & A & 0 & 0 & 1 & 0 & 0 & 1 & 1 & 0 & 0 & $\begin{array}{lll}0 & u_{C A} & -u_{C A}\end{array}$ & $\begin{array}{lll}i_{c} & 0 & -i_{c} \\
\end{array}$ \\
\hline 17 & $\mathrm{C}$ & $\mathrm{C}$ & $\mathrm{B}$ & 0 & 0 & 1 & 0 & 0 & 1 & 0 & 1 & 0 & $0-u_{B C} u_{B C}$ & $\begin{array}{lll}0 & i_{c} & -i_{c} \\
\end{array}$ \\
\hline 18 & A & A & B & 1 & 0 & 0 & 1 & 0 & 0 & 0 & 1 & 0 & $0 \quad u_{A B}-u_{A B}$ & $\begin{array}{ll}-i_{c} i_{c} & 0 \\
\end{array}$ \\
\hline 19 & $\mathrm{~A}$ & A & $\mathrm{C}$ & 1 & 0 & 0 & 1 & 0 & 0 & 0 & 0 & 1 & $\begin{array}{ll}0 & -u_{C A} u_{C A} \\
\end{array}$ & $\begin{array}{lll}-i_{c} & 0 & i_{c} \\
\end{array}$ \\
\hline 20 & $\mathrm{~B}$ & B & $\mathrm{C}$ & 0 & 1 & 0 & 0 & 1 & 0 & 0 & 0 & 1 & $\begin{array}{lll}0 & u_{B C} & -u_{B C}\end{array}$ & $\begin{array}{ll}0 & -i_{c} i_{c}\end{array}$ \\
\hline 21 & $\mathrm{~B}$ & $\mathrm{~B}$ & $\mathrm{~A}$ & 0 & 1 & 0 & 0 & 1 & 0 & 1 & 0 & 0 & $0-u_{A B} u_{A B}$ & $\begin{array}{lll}i_{c} & -i_{c} & 0 \\
\end{array}$ \\
\hline 22 & $\mathrm{~A}$ & $\mathrm{~B}$ & $\mathrm{C}$ & 1 & 0 & 0 & 0 & 1 & 0 & 0 & 0 & 1 & $u_{A B} u_{B C} u_{C A}$ & $i_{a} i_{b} i_{c}$ \\
\hline 23 & A & $\mathrm{C}$ & $\mathrm{B}$ & 1 & 0 & 0 & 0 & 0 & 1 & 0 & 1 & 0 & $-u_{C A}-u_{B C}-u_{A B}$ & $i_{a} i_{c} i_{b}$ \\
\hline 24 & $\mathrm{~B}$ & $\mathrm{~A}$ & $\mathrm{C}$ & 0 & 1 & 0 & 1 & 0 & 0 & 0 & 0 & 1 & $-u_{A B}-u_{C A}-u_{B C}$ & $i_{B} i_{a} i_{c}$ \\
\hline 25 & $\mathrm{~B}$ & $\mathrm{C}$ & A & 0 & 1 & 0 & 0 & 0 & 1 & 1 & 0 & 0 & $u_{B C} u_{C A} u_{A B}$ & $i_{c} i_{a} i_{b}$ \\
\hline 26 & $\mathrm{C}$ & A & $\mathrm{B}$ & 0 & 0 & 1 & 1 & 0 & 0 & 0 & 1 & 0 & $u_{C A} u_{A B} u_{B C}$ & $i_{b} i_{c} i_{a}$ \\
\hline 27 & $\mathrm{C}$ & $\mathrm{B}$ & A & 0 & 0 & 1 & 0 & 1 & 0 & 1 & 0 & 0 & $-u_{B C}-u_{A B}-u_{C A}$ & $i_{c} i_{b} i_{a}$ \\
\hline & & & & & & & & & & & & & 1 & (17) \\
\hline & & & & & & & & & & & & & +1)| & (18) \\
\hline$g=$ & & & & & & & & & & & & & & (19) \\
\hline
\end{tabular}

The selection of the switch combinations for the successive time interval is performed using a quality function " $g$ " minimization technique. For the computation of " $g$ ", the output voltage and input reactive power on the next sampling interval are predicted. 


\section{Simulation Results}

The proposed HT control algorithm with model predictive control has been verified in simulation studies in Matlab Simulink. The simulation parameters are as follows: process discretization time $T_{D}$ is equal $5 \mu \mathrm{s}$, generator voltage $u_{S}=230$ $\mathrm{V} / 50 \mathrm{~Hz}$, inductance of the input filter $L_{S}=0.1 \mathrm{mH} / 0.2 \Omega$, capacitance of the input filter $C_{S}=100 \mu \mathrm{F}$, inductance of the output filter $L_{L}=3 \mathrm{mH} / 0.2 \Omega$, capacitance of the output filter $C_{L}=25 \mu \mathrm{F}$. The tests were carried out for the $R L$ load $R_{Z L}=10 \Omega$ and $L_{Z L}=50 \mathrm{mH}$.

In simulation verification, a converter model built from idealized connectors was used. Simulation files are available from [28]. In addition, discrete models of input and output filters have been implemented. The value of compensation voltages was determined in accordance with the relation (15), by measuring the instantaneous value of the supply voltage. Then, in each sampling period $t_{D}$, the $\underline{i}_{S}$, $\underline{u}_{a b c}$ and $\underline{u}_{C}, \underline{i}_{A B C}$ signals are calculated in accordance with (9), (10), respectively for each of the 27 allowed combinations of matrix converter switches. Out of these 27 results, one combination of switches is activated, for which the objective function " $g$ " (19) has a minimum value. The simplified scheme of MPC for the proposed HT with MC is shown in Fig. 3(a), whereas control flowchart is shown in Fig. 3(b).

Examples of output voltage stabilization during the symmetrical $70 \%$ source voltage sag (observed within $45 \mathrm{~ms}$ to $80 \mathrm{~ms}$ ) and $130 \%$ overvoltage (observed within $80 \mathrm{~ms}$ to $120 \mathrm{~ms}$ ), using the HT with MC and model predictive control are presented in Fig. 4. As is visible in the presented time waveforms, the amplitude of output voltages is constant. Oscillations due to step voltage change are visible only at the moments of initiation and cessation of the voltage sag or overvoltage.

The use of predictive control is also a very simple way of enabling compensation of asymmetric voltage sag and overvoltage. An example of such compensation is shown in Fig. 5 for asymmetrical voltage dip with phase shift and overvoltage in one line. The asymmetrical voltage sag with phase shift in two lines is observed within $40 \mathrm{~ms}$ to $100 \mathrm{~ms}$ in Fig. 5. In addition, in the time from $100 \mathrm{~ms}$ asymmetrical overvoltage in the one line occurs. Without changing the control strategy, it is possible to fully compensate voltage for unbalanced changes in the supply voltage amplitude. We obtain much better results than those presented in reference [10] which uses the classic SVM method. A similar situation occurs during compensation of voltage harmonics [29]. An example of such a situation is shown in Fig. 6 for harmonic distortions at the nominal value of the supply voltage (observed within $40 \mathrm{~ms}$ to $100 \mathrm{~ms}$ ) and $80 \%$ of the supply voltage sag and harmonic distortions (observed within $100 \mathrm{~ms}$ to $140 \mathrm{~ms}$ ). 


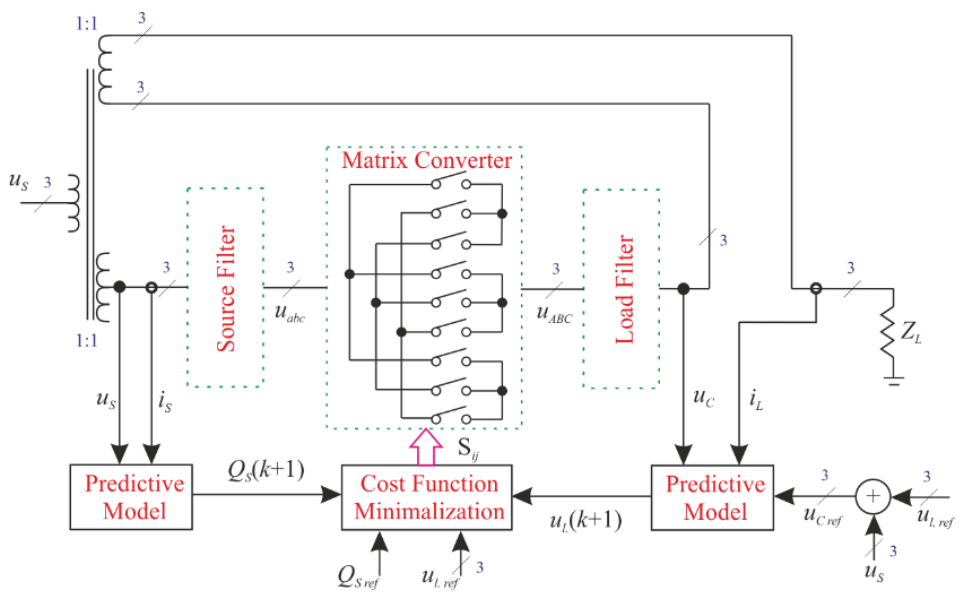

(a)

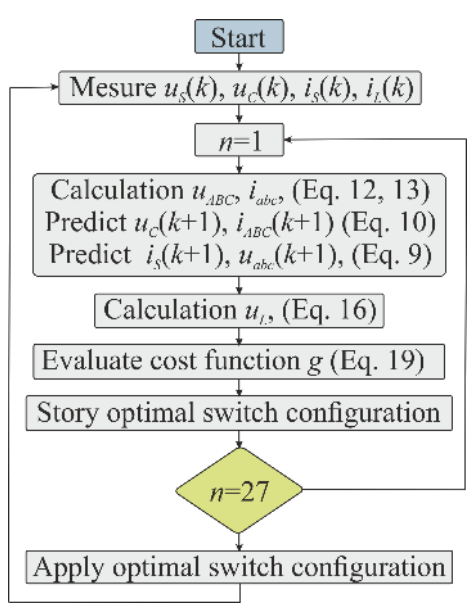

(b)

Figure 3

Blok diagram of the predictive control of HT with MC with minimalization of the output voltage tracking error and input reactive power (a), control flow chart (b) 


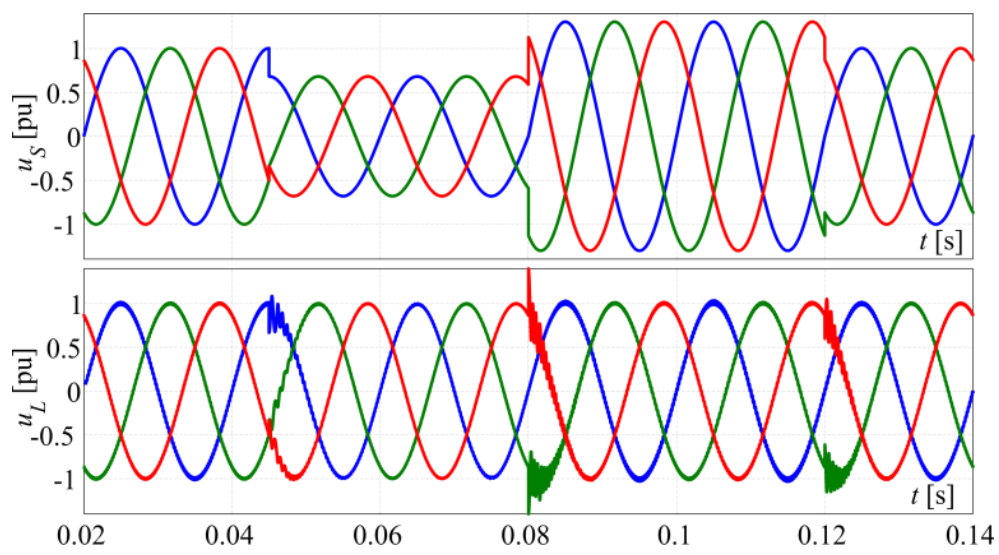

Figure 4

Simulation results of HT source and output voltage time waveforms during $70 \%$ symmetrical source voltage sag and $130 \%$ source symmetrical overvoltage

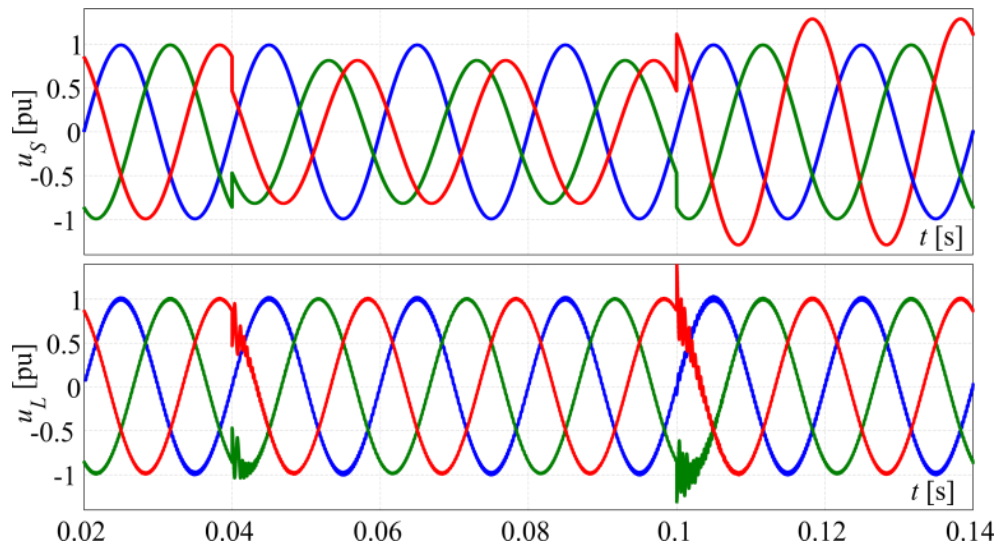

Figure 5

Simulation results of HT source and output voltage time waveforms during $70 \%$ unsymmetrical source voltage sag in two lines with voltage phase shift and $130 \%$ unsymmetrical overvoltage in one line

The obtained result confirms the possibility of compensation for this type of distortion, without additional expansion of the control algorithm, and the result is quite satisfactory. The presented preliminary results of research limited to simulation studies indicate the huge potential of using the predictive method. The next tests will have to take into account additional parameters such as those of the transformer or power network. 

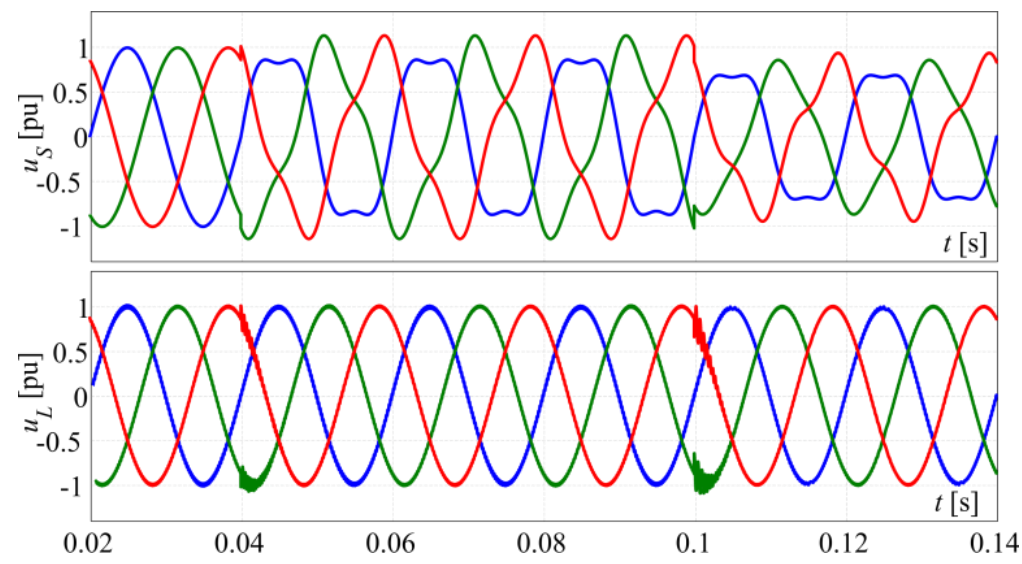

Figure 6

Simulation results of HT source and output voltage time waveforms with harmonic distortion and $80 \%$ voltage sag with harmonic distortion

\section{Limitations and Scope}

The proposed approach has several limitations. Firstly, the implementation of the control system will require a large number of A/D converters and voltage/current sensors to measure three-phase voltages and currents in the compensator circuit. Furthermore, the proposed voltage compensator has some drawbacks, related to the connections of the HT to the same system in which there is a grid fault. Because the system has no energy storage element, the HT needs a minimum network voltage to work properly and it may not be able to compensate very deep sags and large overvoltage.

The proposed model predictive control algorithm does not take into account the transformer parameters that will be important in the control of a real system. The preliminary research results presented in the letter indicate the significantly improved properties of this type of control compared with classical methods based on SVM algorithms.

It should be emphasized that the proposed system can already be easily implemented to protect consumers whose loads are sensitive to voltage fluctuations. The load power range for which a compensator is provided is equal to several dozen $\mathrm{kVA}$. An important issue of future work will be to assess the benefits and costs of the AC voltage compensation system [30]. 


\section{Conclusions}

In this paper, a three-phase hybrid transformer with a matrix converter and model predictive control, for compensation of source voltage sag/swell and harmonics has been presented. The operation and circuit have been described previously in paper [10]. In this letter the main topic is related to the presentation of the proposed automatic control of the analyzed source voltage variations compensator using the model predictive control method. Initial investigation has given very satisfactory results. The preliminary research results presented in the article indicate significantly improved properties for this type of control compared with classical methods based on SVM algorithms [10].

The next step of the research will focus on the theoretical modeling of the electromagnetic transformer which is used in the HT and will take into account the parameters in the predictive control algorithm. In addition, the experimental verification of the properties of the proposed system will be the target of future research. Economic analyzes [31], construction and implementation of the proposed solution in the context of individual, group and central applications will also be considered.

\section{References}

[1] S. C. Vegunta and J. V. Milanovic: Estimation of cost of downtime of industrial process due to voltage sags, IEEE Transactions on Power Delivery, 2011, Vol. 26, No. 2, pp. 576-587

[2] Z. Djokic, J. Desment, G. Vanalme, J. Milanovic, K. Stockman: Sensitivity of personal computer to voltage sags and short interruptions, IEEE Transactions on Power Delivery, 2005, Vol. 20, No. 1, pp. 375-383

[3] O. P. Mahela, A. G. Shaik: Topological aspects of power quality improvement techniques: A comprehensive overview, Renewable and Sustainable Energy Reviews, 2016, Vol. 58, pp. 1129-1142

[4] D. Divan and P. Kandula: Distributed power electronics: An enabler for the future grid, CPSS Transactions on Power Electronics and Applications, 2016, Vol. 1, No. 1, pp. 57-65

[5] A. Tahri, H. M. Boulouiha, A. Allali, T. Fatima: A multi-variable LQG controller-based robust control strategy applied to an advanced static VAR compensator, Acta Polytechnica Hungarica, 2013, Vol. 10, No. 4

[6] J. Burkard, J. Biela: Evaluation of topologies and optimal design of a hybrid distribution transformer, Proceedings of European Conference on Power Electronics and Applications, EPE`15 ECCE Europe, 2015, Geneva, Switzerland, pp. 1-10

[7] D. Das, R. P. Kandula, J. A. Muñoz, D. Divan, R. G. Harley, J. E. Schatz: An integrated controllable network transformer - hybrid active filter 
system, IEEE Transactionon Industrial Application, 2015, Vol. 51, No. 2, pp. 1692-1701

[8] J. Kaniewski, Z. Fedyczak, G. Benysek: AC voltage sag/swell compensator based on three-phase hybrid transformer with buck-boost matrix-reactance chopper, IEEE Transaction on Industrial Electronics, 2014, Vol. 61, No. 8, pp. 3835-3846

[9] T. Kang, S. Choi, A.S. Morsy and P.N. Enjeti: Series voltage regulator for a distribution transformer to compensate voltage sag/swell, IEEE Trans. Ind. Electron, Vol. 64, No. 6, pp. 4501-4510, 2017

[10] P. Szcześniak, J. Kaniewski: Hybrid transformer with matrix converter, IEEE Transactions on Power Delivery, 2016, Vol. 31, No. 3, pp. 1388-1396

[11] P. Szcześniak: The compensator of voltage sage/swell installed in connection terminals of small industrial plant or selected loads,European Conference on Power Electronics and Applications (EPE'17 ECCE Europe) Warsaw, Poland (2017)

[12] P. Szcześniak, J. Kaniewski, P. Sanjeevikumar: Control algorithm concept for AC voltage stabilizer based on hybrid transformer with a matrix converter, Eds. Garg, A., Bhoi, A.K., Sanjeevikumar, P., Kamani, K. K. in: Advances in Power Systems and Energy Management, Singapore: Springer, 2018 (Lecture Notes in Electrical Engineering; Vol. 436) pp. 337-346

[13] J. Andreu, I. Kortabarria, E. Ormaetxea, E. Ibarra, J. L. Martin, S. Apiñaniz: A step forward towards the development of reliable matrix converters, IEEE Transaction on Industrial Electronics, 2012,Vol. 59, No. 1, pp. 167-183

[14] D. Zieliński, P. Lipnicki, W. Jarzyna: Synchronization of voltage frequency converters with the grid in the presence of notching, COMPEL: The International Journal for Computation and Mathematics in Electrical and Electronic Engineering, 2015, Vol. 34, pp. 657-673

[15] M. Bobrowska-Rafal, K. Rafal, M. Jasinski, M. P. Kazmierkowski: Grid synchronization and symmetrical components extraction with PLL algorithm for grid connected power electronic converters - a review, Bulletin of the Polish Academy of Sciences Technical Sciences, 2011, Vol. 59, No. 4, pp. 485-497

[16] J. A. Tenreiro Machado, B. Pátkai, I. J. Rudas: Intelligent Engineering Systems and Computational Cybernetics, Springer Netherlands 2009

[17] R. E Precup, S. Preitl, E. M. Petriu, J. K. Tar, M. L. Tomescu, C. Pozna: Generic two-degree-of-freedom linear and fuzzy controllers for integral processes, Journal of the Franklin Institute, 2009, Vol. 346, No. 10, pp. 980-1003 
[18] S. Vrkalovic1, E. C. Lunca, I. D. Borlea: Model-free sliding mode and fuzzy controllers for reverse osmosis desalination plants, International Journal of Artificial Intelligence, 2018, Vol. 16, No. 2, pp. 208-222

[19] R. E. Precup, S. Preitl: Stability and sensitivity analysis of fuzzy control systems. Mechatronics applications, Acta Polytechnica Hungarica, 2006, Vol. 3, No. 1, pp. 61-76

[20] A. Ürmös, Z. Farkas, M. Farkas, T. Sándor, L. T. Kóczy, Á. Nemcsics: Application of self-organizing maps for technological support of droplet epitaxy, Acta Polytechnica Hungarica, 2017, Vol. 14, No. 4, pp. 207-224

[21] S. Padmanaban, F. J. L. Daya, F. Blaabjerg, P. W. Wheeler, P. Szcześniak, V. Oleschuk, A. H. Ertas, Wavelet-fuzzy speed indirect field oriented controller for three-phase AC motor drive - Investigation and implementation, Engineering Science and Technology, an International Journal, 2016, Vol. 19, No. 3, pp. 1099-1107

[22] B. Lantos, Z. Bodó, High level kinematic and low level nonlinear dynamic control of unmanned ground vehicles, Acta Polytechnica Hungarica, 2019, Vol. 16, No. 1, pp. 97-117

[23] M. Trojanová, A. Hošovský, Comparison of different neural networks models for identification of manipulator arm driven by fluidic muscles, Acta Polytechnica Hungarica, 2018, Vol. 15, No. 7, pp. 7-28

[24] E. Tóth-Laufer, M Takács, I. J. Rudas, Fuzzy logic-based risk assessment framework to evaluate physiological parameters, Acta Polytechnica Hungarica, 2015, Vol. 12, No. 2, pp. 159-178

[25] J. Rodríguez, P. Cortes: Predictive Control of Power Converters and Electrical Drives. John Wiley \& Sons, 2012

[26] M. R. Nasiri, S. Farhangi, J. Rodríguez, Model predictive control of a multilevel CHB STATCOM in wind farm application using diophantine equations, IEEE Transaction on Industrial Electronics, 2019, Vo. 66, No. 2, pp. $1213-1223$

[27] P. Wheeler, M. Rivera, S. Toledo: An indirect model predictive current control for a direct matrix converter with instantaneous reactive power minimization, Proceedings of IEEE Southern Power Electronics Conference (SPEC'2017) Puerto Varas, 2017, pp. 1-6

[28] https://www.mathworks.com/matlabcentral/fileexchange/71962-modelpredictive-control-hybrid-converter-with-matrix-conver

[29] S. Yusoff, L. De Lillo, P. Zanchetta, P. Wheeler: Predictive control of a direct AC/AC matrix converter power supply under non-linear load conditions, Proceedings of $15^{\text {th }}$ International Power Electronics and Motion Control Conference (EPE/PEMC'2012) Novi Sad, 2012, pp. DS3c.4-1DS3c.4-6 
[30] N. Katic: Performance Analysis of smart grid solutions in distribution power systems, Acta Polytechnica Hungarica, 2018, Vol. 15, No. 6

[31] W. E. Brumsickle, R. S. Schneider, G. A. Luckjiff, D. M. Divan, M. F. McGranaghan, Dynamic sag correctors: cost-effective industrial power line conditioning, IEEE Transactions on Industry Applications, 2001, Vol. 37, No. 1, pp. 212-217 